\section{PRENATAL CARE}

DEDUCTIONS FROM THE STUDY OF THREE THOUSAND FOUR HUNDRED AND SIXTEEN CASES *

MARY LEE EDWARD, B.A., M.B. Assistant Attending Obstetrician at the Infirmary for Women and Children

NEW YORK

The infant mortality statistics in the New York Infirmary for Women and Children seem worth publishing at this time when prenatal care is receiving so much attention, partly because we have had a regular prenatal clinic for over twenty years, and also because the results show a gradual general improvement, following increased care and improved facilities in the clinic.

The accompanying table shows statistics of the stillbirths and the deaths, within two weeks, for the last eight years since the rebuilding of the hospital.

MORTALITY STATISTICS FOR THE PAST EIGHT YEARS

$\begin{array}{lccccc}\text { Year } & \begin{array}{c}\text { Infants } \\ \text { Born }\end{array} & \begin{array}{c}\text { Still } \\ \text { Births }\end{array} & \begin{array}{c}\text { Per Cent. } \\ \text { of Births }\end{array} & \begin{array}{c}\text { Deaths First } \\ 14 \text { Days }\end{array} & \begin{array}{c}\text { Per Cent. } \\ \text { of Those } \\ \text { Born Alive }\end{array} \\ 1907 & 146 & 5 & 3.4 & 9 & 6.38 \\ 1908 & 280 & 12 & 4.2 & 10 & 3.7 \\ 1909 & 357 & 19 & 5.3 & 9 & 2.6 \\ 1910 & 374 & 19 & 4 & 9 & 2.5 \\ 1911 & 523 & 26 & 4.9 & 10 & 2 \\ 1912 & 552 & 14 & 2.5 & 13 & 2.4 \\ 1913 & 587 & 20 & 3.4 & 11 & 1.9 \\ 1914 & 597 & 15 & 2.5 & 18 & \mathbf{3} \\ & \mathbf{3 , 4 1 6} & \mathbf{1 2 6} & \mathbf{3 . 6} & \mathbf{8 9} & \mathbf{2 . 7}\end{array}$

Total mortality, 215 , or 6.3 per cent.

Our total percentage of stillbirths is 3.6 as compared with 4.29 per cent. in Sloane Hospital and 5.22 per cent. in the Universitäts Frauenklinik in Munich (quoted by Holt and Babbitt ${ }^{1}$ ). The percentage of deaths in the first fourteen days is 2.7 as compared with the 3.1 per cent. in Sloane Hospital. The total mortality of 6.3 per cent. is perhaps not so much of an improvement over Williams' 7 per cent. ${ }^{2}$ as our approach to his description of an ideal clinic should warrant. It is, however, a step in the right direction, and the fact that our mortality tends to decrease is encouraging.

The 215 cases were divided as follows:

Abortions (under $37.5 \mathrm{~cm}$. or $1,500 \mathrm{gm}$.) ...........32

Premature ( 37.5 to $46 \mathrm{~cm}$. or 1,500 to $2,500 \mathrm{gm}$.)...... 44

Full term ( $46 \mathrm{~cm}$. or $2,500 \mathrm{gm}$. or over) ........... 125

Development unrecorded $\ldots \ldots \ldots \ldots \ldots \ldots \ldots \ldots \ldots .14$

Exclusive of the thirty-two abortions, in thirty-four cases no heart was heard on admission and, of these, twenty-one fetuses were macerated. Thirty-nine of those born alive, or 1.1 per cent., died the first day; 2.1 per cent. (seventy-three) during the first seven days, and 2.7 per cent. during the first two weeks. The causes of early mortality, with the exception of

* Seen in the obstetric service of the New York Infirmary for Women and Children.

1. Holt, L. Emmett, and Babbitt, Ellen C.: Institutional Mortality of the New-Born, A Report on Ten Thousand Consecutive Births at the Sloane Hospital for Women, New York, Tre Journal A. M. A., Jan. 23, 1915, p. 287.

2. Williams, J. Whitridge: The Limitations and Possibilities of Prenatal Care Based on the Study of 705 Fetal Deaths Occurring in 10,000

Consecutive Admissions to the Obstetrical Department of the Johns Hopkins Hospital, Thz Journal A. M. A., Jan. 9. 1915, p. 95. one case in which the necropsy report gave meningitis, did not differ from the cause of stillbirth.

The causes of total mortality are:

Labor (forceps 27 ; cranitomy 3 ; rigid cervix 2 ; breech 13 , with 2 impacted; long labor 7 ; shoulder 1 ; early induction 2 ; fibroid of cervix 1 ; polyp of cervix 1 ; flat pelvis with version 1 ; placenta praevia 14 ; prolapsed cord 12, with 2 pulseless; cord about neck 6 ; concealed or accidental hemorrhage 3) 93 , or 43 per cent.

Syphilis ......................14, or 6.5 per cent.

Undetermined $\ldots \ldots \ldots \ldots \ldots \ldots \ldots 28$, or 13 per cent.

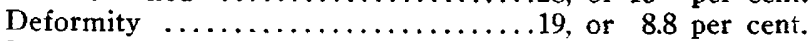

Prematurity and inanition.........20, or 9.3 per cent.

Toxemia ..................... 7

Asphyxia $\ldots \ldots \ldots \ldots \ldots \ldots \ldots \ldots \ldots 6$

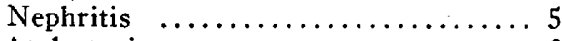

Atalectasis $\ldots \ldots \ldots \ldots \ldots \ldots \ldots . \ldots 3$

Cerebral hemorrhage ............ 4

Endocarditis in mother $\ldots \ldots \ldots \ldots \ldots 3$

From other causes ..............13

The other causes were ten in number and were acute hydramnios, with labor induced, 2 twins) pertussis in mother 2, typhoid in mother 1 , general infection 1 , intra-uterine infection 2 , intraventricular hemorrhage 1 , meningitis 1 , perisplenitis 1 , hemorrhages into brain, lungs, liver, etc., 1, edema of the brain 1.

\section{LABOR AS FACTOR}

The largest of these groups deserves special mention. The percentage caused by labor, while not unusually large, shows possibilities of reduction. Unfortunately, most of these possibilities occur at the actual time of delivery and not in prenatal care. Here the question of personnel is a large factor, for we have a teaching hospital with a changing house staff. In ten of the cases of prolapsed cord, for instance, judgment and dexterity might have done much to save the fetus. In eleven of the cases of breech extraction, a slight delay or a false movement may have been to blame. Placenta praevia causes a comparatively large infant mortality, as, through fear of infection, we do not undertake cesarean section. The deaths incident to forceps deliveries might possibly have been lowered in private practice, but the figures here given include cases of dystocia from the cervix as well as from the bony pelvis. In some of these, delay may have been a factor through nonobservance of the earliest change in tone or rate of the fetal heart; in others, permission for cesarean section or induction was withheld; but the large majority were borderline cases--either flat pelves with a true conjugate of $8.5 \mathrm{~cm}$. or justominor pelves in which the disproportion did not seem to warrant cesarean section. The question is often one for close consideration.

\section{SYPHILIS}

Our percentage from syphilis is comparatively small, 6.5 as compared to Williams' 26.4 per cent. 'The latter percentage is, however, due to the fact that of the patients composing the Baltimore clinic almost half are colored. Moreover, some patients in our undetermined class of 13 per cent. were probably syphilitic. In any case, making all allowances, it seems positive that treatment has lowered the mortality.

Cases of deformity, monsters, etc., except for the treatment of a possible underlying syphilis, offer no hope of reduction with our present knowledge. Unfortunately, even when syphilis is treated, the time is often too late to correct any embryonic defect. 
The cases of prematurity and inanition undoubtedly depend on poor home surroundings of the mother. Five of the twenty cases were twin births and naturally the infants had a poorer chance to survive, but the large factor is probably sociologic and through the clinic the social service is able to help in these cases.

\section{CLINICAL MANAGEMENT}

The prenatal clinic, as at present managed, is under the direct supervision of the attending obstetrician. The assistant in the department and the intern follow the cases. Complications, such as tuberculosis, endocarditis, hyperthyroidism, abscess, etc., are looked after in conjunction with the doctors of the other departments of the dispensary, as deemed advisable. We have no prenatal visiting nurses, but the social service cares for patients who seem in need. Medical instructions are given by the doctors.

Patients register at seven months, sometimes at six months; they make bimonthly visits till the end of the eighth month and weekly visits during the last month. Patients not reporting for a period of a month are debarred. The patient's history is taken at the first visit, especially as to history of past diseases, former labors or abortions, and health during present pregnancy. The physical examination, unless otherwise indicated, is obstetric only, consisting of external and internal pelvic measurements and abdominal palpation, mensuration and auscultation. In making the internal examination, the condition of the cervix and perineum is noted and any erosion of the former is treated.

Syphilis is conceded to be the largest single factor in prenatal death, and while we are not able to treat patients in the early months, every registered patient presenting any symptoms or giving any history suspicious of syphilis has a Wassermann examination and if complement fixation be positive, has a course of salvarsan. The history we most commonly get in positive cases is one of abortion, stillbirths, or children dying in early life-often of "infant's consumption."

Furthermore, accurate or at least careful pelvic measurements help to reduce the cases of dystocia, due to the bony pelvis, to a minimum, for while no one's judgment is infallible, early observation allows more intelligent treatment.

Routine urinalyses have enabled us to eliminate toxemia almost entirely, some of the seven cases being early inductions in patients not responding to treatment, others being emergencies. In albuminuria cases, the blood pressure is our main guide and where it remains increasingly high, in spite of eliminative treatment, labor is induced.

Finally, instructions as to personal hygiene and care, we believe, prevent many cases of septicemia and mastitis in mothers, with consequent good effect on the infants.

\section{CONCLUSION}

I believe we are repaid for continuing our prenatal clinic and striving to improve it; that it is one of the most important features of the obstetric department; that prenatal care, though it seem thankless, has very definite results, and that it is often by such painstaking attention that we accomplish most.

150 East Thirty-Fifth Street.

\section{OBSERVATIONS ON INCIPIENT HYPER- TROPHY OF THE PROSTATE}

\author{
ABRAHAM L, WOLBARST, M.D. \\ NEW YORK
}

The diagnosis of beginning prostatic hypertrophy is not always a simple matter, particularly in the hands of the general practitioner, and occasionally in the hands of the urologist. Especially is one apt to find these diagnostic errors in cases involving the nervous system, in which functional disturbances of the bladder are the prevailing symptoms. Such errors are liable to occur when one fails to remember that spinal cord disease often gives the first evidence of its existence by the development of disturbances in the urinary and sexual functions. In such cases, it is not to be wondered at that errors occur, but there can be no doubt that they can be reduced to a minimum, even to zero, if due precautions are taken.

\section{CASE REPORT}

A case of this kind, which occurred in my experience, illustrates this point rather strikingly:

The patient was a man, aged 49, married twelve years, the father of five healthy children. He had been perfectly well up to a year previously, when he noticed a weakening of the urinary stream, an increased frequency in the desire to urinate, and a delay in starting the stream. His family physician made the diagnosis of prostatic hypertrophy, and took him to a urologist for confirmation. The urologist performed a cystoscopy, found a prostatic enlargement, with bladder trabeculations, confirmed the diagnosis, and recommended prostatectomy. The patient, thoroughly alarmed at the prospect of a surgical operation for an ailment which was not giving him much annoyance, determined to seek another opinion, and thus came under my observation.

The patient was still a young man, physically and mentally, and when he stated that he came for the purpose of confirming the diagnosis and approving of the operative suggestion, the first thought was that this was a young man, indeed, to have his prostate removed, hypertrophy notwithstanding. Cystoscopy was not undertaken; I believe that cystoscopy is not necessary in the diagnosis of prostatic hypertrophy, when other diagnostic elements are available. In this particular case, hypertrophy did not appear probable after the following data were obtained: urine clear, residuum three-fourths ounce, urethral length $7 \frac{1}{2}$ inches, no nocturnal call to urinate. The prostate was slightly enlarged by rectum; there was no stricture in the urethra.

Physical examination added something useful to these unsatisfactory data. The knee-jerk was totally absent, pupils dilated unequally, slight Romberg present. Further questioning elicited the information that twenty years previously the patient had a penile ulcer, which soon passed away. He received internal treatment of some kind for about a year, but had not taken any since then. Wassermann, four plus.

With this information at hand, I made a diagnosis of incipient tabes dorsalis, and referred the patient to Dr. Joseph Fraenkel, who confirmed the diagnosis, and under whose care the patient has been doing very nicely for the past two years. At the present writing, the patient does not show any evidence of prostatic hypertrophy, except as stated above.

USE OF THE CYSTOSCOPE

This case teaches us several lessons. First, mere enlargement of the prostate as seen with the cystoscope does not necessarily demand immediate prostatectomy. This will be discussed later on. Secondly, the cystoscope, with all its great usefulness, still has its limitations, and one of these, in my opinion, is in the diagnosis of prostatic hypertrophy. I am conservative 